AperTO - Archivio Istituzionale Open Access dell'Università di Torino

Pretreatment serum hemoglobin level as a predictive factor of response to neoadjuvant chemotherapy in patients with locally advanced squamous cervical carcinoma: a preliminary report

This is the author's manuscript

Original Citation:

Availability:

This version is available http://hdl.handle.net/2318/10675

since

Terms of use:

Open Access

Anyone can freely access the full text of works made available as "Open Access". Works made available under a Creative Commons license can be used according to the terms and conditions of said license. Use of all other works requires consent of the right holder (author or publisher) if not exempted from copyright protection by the applicable law. 
Original Research Report

\title{
Pretreatment serum hemoglobin level as a predictive factor of response to neoadjuvant chemotherapy in patients with locally advanced squamous cervical carcinoma: A preliminary report
}

\author{
Luca Fuso, Simona Mazzola, Francesco Marocco, Annamaria Ferrero, Daniela Dompè, \\ Alice Peroglio Carus, Paolo Zola* \\ Unit of Gynecologic Oncology, Department of Obstetrics and Gynecology, University of Turin, \\ Azienda Sanitaria Ospedaliera Ordine Mauriziano, "Umberto I" Hospital, \\ Torino and Institute for Cancer Research and Treatment, Candiolo (TO), Largo Jurati 62, 10138 Turin, Italy
}

Available online 26 September 2005

\begin{abstract}
Objective. The aim of this study was to evaluate the predictive value of pretreatment serum hemoglobin level (Hb) together with a series of clinical and pathological variables available before neoadjuvant chemotherapy in locally advanced squamous cervical cancer.

Methods. The influence on response to neoadjuvant chemotherapy of a series of pretreatment clinico-pathological features: hemoglobin level at diagnosis, age, parity, menopausal status, body mass index, clinical stage, tumor diameter, and nuclear grading were analyzed on 73 patients with locally advanced cervical cancer treated with platinum-based neoadjuvant chemotherapy followed by radical surgery. The relationships between pretreatment variables and response to chemotherapy were assessed in univariate and multivariate settings. A univariate and multivariate logistic regression model was adapted to predict an "optimal" response (pathological complete response or more than $50 \%$ reduction in tumoral diameter) or "sub-optimal" response $(<50 \%$ reduction in tumoral diameter).

Results. Seventy-three patients—clinical stage: Ib2: 29 (39.7\%) IIa: 22 (30.1\%) IIb: 22 (30.1\%)—received 3 cycles of platinum-based neoadjuvant chemotherapy followed by type III radical hysterectomy. A complete response to neoadjuvant chemotherapy was significantly associated with higher level of pretreatment hemoglobin (mean $14.0 \mathrm{mg} / \mathrm{dl}$ ) compared to patients with $\geq 50 \% \mathrm{response}(12.7 \mathrm{mg} / \mathrm{dl}) \mathrm{or}<50 \%$ $(11.9 \mathrm{mg} / \mathrm{dl})(P=0.002)$. At multivariate analysis, Hb level was found to be the most powerful and significantly related factor to response to neoadjuvant chemotherapy. A hemoglobin threshold of $12 \mathrm{mg} / \mathrm{dl}$ was able to distinguish between patients - with $\geq 12 \mathrm{mg} / \mathrm{dl}-\mathrm{at}$ higher probability to respond to neoadjuvant chemotherapy from the ones at lower probability (hemoglobin level under $12 \mathrm{mg} / \mathrm{dl}$ ). Patients with a complete response to chemotherapy had a $100 \%$ survival compared to $93.1 \%$ and $53.8 \%$ for patients with responses $\geq 50 \%$ and $<50 \%$ respectively $(P=0.0001)$. Patients with a pretreatment hemoglobin level of $\geq 12 \mathrm{mg} / \mathrm{dl}$ showed a survival of $87 \%$ compared to $63 \%$ for patients with a lower hemoglobin level $(P=0.008)$.

Conclusions. Pretreatment $\mathrm{Hb}$ level showed a prognostic and independent predictive value for response to neoadjuvant chemotherapy in locally advanced cervical cancer. In our preliminary report, performed on a limited sample, a threshold of $12 \mathrm{mg} / \mathrm{dl} \mathrm{seems}$ to be helpful to distinguish between "optimal" and "non-optimal" response.
\end{abstract}

(C) 2005 Elsevier Inc. All rights reserved.

Keywords: Hemoglobin; Response to chemotherapy; Locally advanced squamous cervical cancer

\footnotetext{
* Corresponding author.

E-mail address: casazola@libero.it (P. Zola).
}

\section{Introduction}

Cervical cancer is the third most common gynecological malignancy in the developed world. Locally advanced disease often shows a 5 -year overall survival of $<70 \%$ [1]. Multimodal treatment strategies, including concomitant 
Table 1

Univariate analysis for response to chemotherapy

\begin{tabular}{|c|c|c|c|c|}
\hline Clinical parameter & $\mathrm{CR}$ & $\geq 50 \%$ & $<50 \%$ & $P$ value \\
\hline Age (mean) & 47.7 & 52.1 & 47.4 & $0.30^{\mathrm{a}}$ \\
\hline $\begin{array}{l}\text { Parity (mean } \\
\qquad(\text { mean rank)) }\end{array}$ & $3.0(46.4)$ & $2.1(36.2)$ & $1.8(31.4)$ & ${\underline{0.05^{\mathrm{b}}}}$ \\
\hline $\begin{array}{l}\text { Menopausal } \\
\text { status }(\%)\end{array}$ & 29.4 & 44.1 & 26.5 & $0.30^{\mathrm{c}}$ \\
\hline BMI (mean) & 25.5 & 24.4 & 24.6 & $0.57^{\mathrm{a}}$ \\
\hline Stage $(\%)$ & & & & $0.86^{\mathrm{c}}$ \\
\hline $\mathrm{Ib}^{2}$ & $9(31.0)$ & $10(34.5)$ & $10(34.5)$ & \\
\hline IIa & $5(22.7)$ & $9(40.9)$ & $8(36.4)$ & \\
\hline $\mathrm{IIb}$ & $4(22.2)$ & $10(34.5)$ & $9(30.8)$ & \\
\hline Grading (\%) & & & & $0.27^{\mathrm{c}}$ \\
\hline 1 & - & $1(3.4)$ & - & \\
\hline 2 & 7 (38.9) & $7(24.1)$ & $13(50.0)$ & \\
\hline 3 & $11(61.1)$ & $21(72.4)$ & $13(50.0)$ & \\
\hline $\begin{array}{l}\text { Tumor } \\
\text { diameter-cm } \\
\text { (mean) }\end{array}$ & 56.6 & 52.9 & 53.4 & $0.57^{\mathrm{a}}$ \\
\hline $\begin{array}{l}\text { Hb pretreatment } \\
\text { level-mg/dl } \\
\text { (mean) }\end{array}$ & 13.8 & 12.7 & 11.9 & $\underline{0.002^{\mathrm{a}}}$ \\
\hline
\end{tabular}

CR: complete response; $\geq 50 \%$ : reduction of tumoral diameter of $50 \%$ or more after NACT; $<50 \%$ : reduction of tumoral diameter of $<50 \%$ after NACT. Underscored: statistical significant at 0.05 level (2-sided).

${ }^{\text {a }} F$ test (ANOVA).

b $U$ test (Kruskal-Wallis test).

c Pearson's Chi-square test.

cisplatin-based chemotherapy and radiotherapy or neoadjuvant chemotherapy followed by radical surgery or by a combination of concurrent chemoradiation and surgery had been claimed to improve survival and local control rates [2]. Neoadjuvant chemotherapy (NACT) followed by radical surgery (RS) has received increasing attention, being demonstrated to be feasible, and the outcome has been improved. In particular, the operability rate rose from $48 \%$ to $100 \%$ after NACT with no influence on surgery-related morbidity. The observed 5-year survival rate in patients treated with NACT followed by surgery was higher than in an exclusive radiation therapy group by $65 \%$ versus $46 \%$ [3-5]. Some efforts have sought to predict chemotherapy resistance by assessing biochemical factors related to tumor cell biology and tumor aggressiveness [6-8]. The respective merits of these treatments will be clarified when the results of new ongoing randomized controlled trials will be available.

Anemia is the most frequently observed hematological abnormality factor among cancer patients; however, its impact on tumor biology is not well understood. Several recent retrospective clinical studies showed that anemia is not only a negative prognostic factor, impairing disease-free and overall survival, but also a negative predictive parameter in radiotherapy-treated patients with solid tumors, including carcinoma of the cervix [9]. Many reports have documented a correlation between $\mathrm{Hb}$ levels before and during treatment and the response to chemotherapy [10], suggesting low $\mathrm{Hb}$ level as a negative predictive parameter in chemotherapy-treated patients affected by several solid tumors. It is postulated that lower $\mathrm{Hb}$ levels resulting in decreased oxygen carrying capacity may lead to increased tumor hypoxia, chemotherapy resistance, and increased tumor angiogenesis [11].

The aim of this report is to investigate whether a relationship exists between pretreatment $\mathrm{Hb}$ levels and response to neoadjuvant chemotherapy in patients treated with NACT and radical surgery. Other pretreatment clinical variables, possibly predictive of chemotherapy response, are investigated.

\section{Methods}

Seventy-three patients with locally advanced cervical cancer, staged $\mathrm{Ib} 2-\mathrm{IIb}$, underwent neoadjuvant chemotherapy followed by radical surgery at the Gynecology Oncology department of the University of Turin between 1997 and 2004 (see Table 1). Data were collected in a database and entered with the following fields: FIGO stage $\mathrm{Ib} 2-\mathrm{IIb}$ disease, histologically confirmed squamous cervical cancer, no previous radiation, treatment with neoadjuvant chemotherapy followed by radical surgery (type III radical hysterectomy and pelvic and paraortic lymphadenectomy), availability of the following pretreatment variables: hemoglobin level at diagnosis, age, parity, menopausal status, body mass index, clinical FIGO stage, tumor diameter, nuclear grading on tumor biopsies, response to chemotherapy according to RECIST criteria for solid tumors, and follow-up data. The response to chemotherapy was reclassified as complete response (disappearance of all microscopic neoplastic foci with negative lymph nodes), tumor load reduction of more than $50 \%$ (reduction of the maximum tumoral diameter of more than $50 \%$ compared to the initial measurement), tumor load reduction of $<50 \%$ (reduction of the maximum tumoral diameter of $<50 \%$ compared to the initial measurement). Patients were all

Table 2

Univariate logistic analysis for "non-optimal" response to chemotherapy $(<50 \%$ reduction $)$

\begin{tabular}{llll}
\hline Clinical pretreatment parameter & HR & CI 95\% ${ }^{\mathrm{a}}$ & $P$ value \\
\hline Age & 0.98 & $0.94-1.05$ & 0.21 \\
Parity & 0.71 & $0.48-1.05$ & 0.09 \\
Menop status & 2.14 & $0.79-5.77$ & 0.13 \\
BMI & 0.98 & $0.85-1.12$ & 0.78 \\
Stage & & & 0.98 \\
$\quad$ Ib2 & 1 & & \\
$\quad$ IIa & 1.08 & $0.34-3.45$ & \\
$\quad$ IIb & 1.08 & $0.34-3.45$ & \\
Grading $(\%)$ & & & 0.25 \\
$\quad 1$ & 1 & & \\
$\quad 2$ & 0.05 & $0.00-2.85$ & \\
$\quad 3$ & 2.28 & $0.84-6.16$ & \\
Tumor diameter (cm) & 0.99 & $0.95-1.03$ & 0.76 \\
Hb pretreatment level mg/dl (continuous) & 0.66 & $0.49-0.90$ & 0.008 \\
Hb $\geq 12 \mathrm{mg} / \mathrm{dl}$ & 1 & & \\
Hb $<12 \mathrm{mg} / \mathrm{dl}$ & 6.83 & $2.16-21.60$ & 0.001 \\
\hline
\end{tabular}

HR: hazard ratio.

${ }^{\text {a }}$ CI: $95 \%$ confidence interval. 
Table 3

Multivariate logistic analysis for "non-optimal" response to chemotherapy

\begin{tabular}{llllll}
\hline $\begin{array}{l}\text { Variables in } \\
\text { the equation }\end{array}$ & HR & CI 95\% ${ }^{\mathrm{a}}$ & Wald & $\begin{array}{l}-2 \log \\
\text { likelihood }\end{array}$ & $P$ value \\
\hline $\begin{array}{l}\text { Hb pretreatment } \\
\text { level } \mathrm{mg} / \mathrm{dl} \\
\quad \text { continuous) }\end{array}$ & 0.66 & $0.49-0.90$ & 6.88 & 87.2 & 0.008 \\
$\mathrm{Hb} \geq 12 \mathrm{mg} / \mathrm{dl}$ & 1 & & & & \\
$\mathrm{Hb}<12 \mathrm{mg} / \mathrm{dl}$ & 6.83 & $2.16-21.60$ & & & 0.001 \\
\hline
\end{tabular}

HR: hazard ratio.

${ }^{\text {a }}$ CI: $95 \%$ confidence interval.

treated with a platinum-based chemotherapy giving at least a dose intensity of $20 \mathrm{mg} / \mathrm{m}^{2} /$ weekly for 3 courses every 21 days. The study protocol had been reviewed by the ethics committee, and written informed consent was obtained from each patient. The relationships between the pretreatment variables and response to chemotherapy were assessed in a univariate setting by means of analysis of variance (ANOVA) for continuous variables and Mann-Whitney non-parametric test to evaluate whether two independent samples are from the same population. A univariate and multivariate logistic regression model is adapted to predict an optimal response (complete or more than $50 \%$ reduction) or a suboptimal response ( $<50 \%$ reduction) based on values of a set of pretreatment predictor variables. The Kaplan-
Meier model, based on estimating conditional probabilities at each time point when an event occurs, is used to estimate the survival rate of patients with a good and poor response to chemotherapy. Actuarial survival curves are generated, and the log rank test is adapted for comparing the equality of survival distributions. Calculations were executed with the SPSS statistical package version 12 (SPSS Inc, IL, USA).

\section{Results}

Seventy-three patients received neoadjuvant chemotherapy. The distribution of clinical stage was as follows: stage Ib2: 29 (39.7\%), IIa: 22 (30.1\%), IIb: 22 (30.1\%). Overall mean age was 49.3 years, and median parity number was 2 . Thirty-four patients $(46.6 \%)$ were menopausal when entering the study. The mean body mass index (BMI) was 24.3 $\mathrm{kg} / \mathrm{m}^{2}$. The grade of differentiation at diagnostic biopsies was as follows: $\mathrm{G} 1=1$ patient $(1.4 \%), \mathrm{G} 2=27$ patients $(37.0 \%), \mathrm{G} 3=45$ patients $(61.6 \%)$. Tumor diameter at diagnostic procedure had an overall median value of $50 \mathrm{~cm}$; 17 patients $(23.3 \%)$ had a neoplasm less than $5 \mathrm{~cm}$ and 56 patients $\geq 5 \mathrm{~cm}(76.7 \%)$. The response to chemotherapy was complete in $18(24.7 \%)$ patients, $\geq 50 \%$ in $29(39.7 \%)$, and $<50 \%$ in $26(35.6 \%)$ patients.

Survival by response to chemotherapy

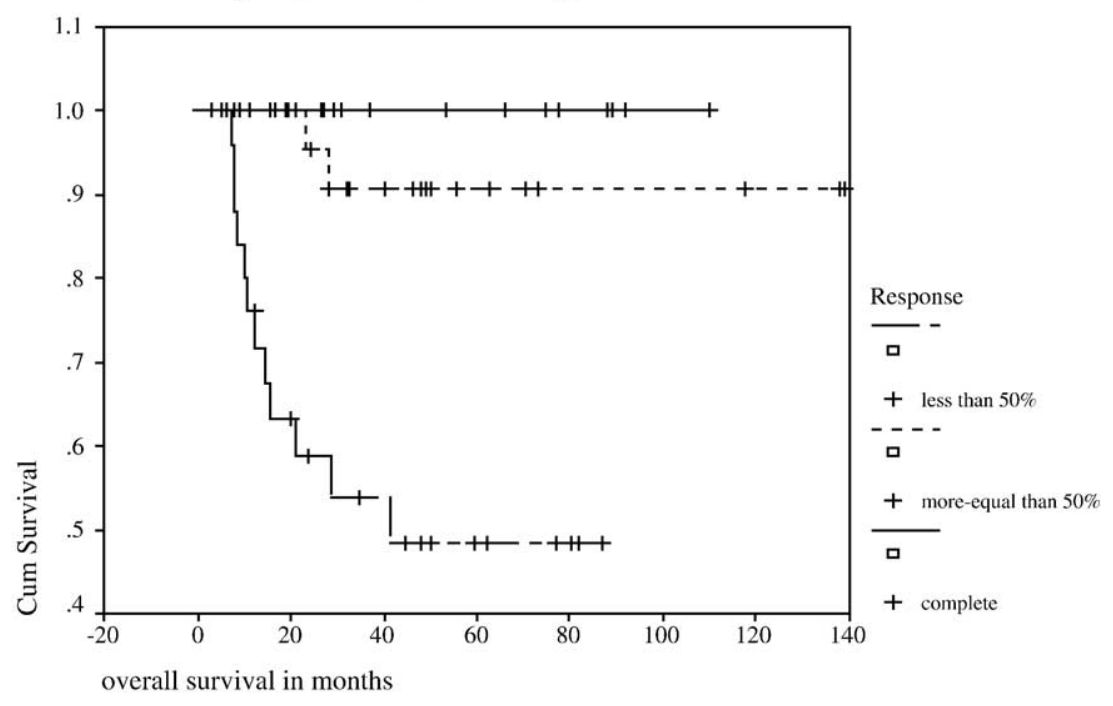

Survival Analysis for response to chemotherapy

\begin{tabular}{lcccc}
\hline & Total & $\begin{array}{l}\text { Number } \\
\text { Events }\end{array}$ & $\begin{array}{l}\text { Number } \\
\text { Censored }\end{array}$ & $\begin{array}{l}\text { Percent } \\
\text { Censored }\end{array}$ \\
\hline Complete response & 18 & 0 & 18 & 100.00 \\
More/equal 50\% response & 29 & 2 & 27 & 93.10 \\
Less than 50\% response & 26 & 12 & 14 & 53.85 \\
Overall & 73 & 14 & 59 & 80.82
\end{tabular}

Log Rank =Statistic: $19.47 \quad \mathrm{p}=0.0001$

Fig. 1. Survival curves and analysis for this patient group to stratified by response to chemotherapy. 
Table 1 shows a univariate analysis for response to chemotherapy in which the distribution of each predictive factor is observed across the three levels of response: complete, $\geq 50 \%,<50 \%$. Patients who demonstrated a complete response had a significantly higher level of pretreatment hemoglobin $(13.8 \mathrm{mg} / \mathrm{dl})$ compared to patients with a $\geq 50 \%$ response $(12.7 \mathrm{mg} / \mathrm{dl})$ or $<50 \%(11.9 \mathrm{mg} / \mathrm{dl}$; $P=0.002)$. A trend towards a better response is also noticed for patients with a higher parity $(P=0.05)$. Table 2 reports a logistic model created to derive the hazard ratio for a nonoptimal response, considered when a $<50 \%$ reduction in tumor measurement was encountered. The dichotomous dependent variable had the following distribution: $64.4 \%$ (47/73 patients) showed complete response or $\geq 50 \%, 35.6 \%$ showed $<50 \%$ response (26/73 patients). For each explanatory pretreatment variable, the hazard ratio of $<50 \%$ response and $95 \%$ confidence interval are displayed. At multivariate analysis (Table 3), $\mathrm{Hb}$ level is the most powerful and significantly related factor to response to chemotherapy. A patient with an $\mathrm{Hb}$ level increment of 1 $\mathrm{mg} / \mathrm{dl}$ had her risk of not responding to platinum-based chemotherapy decreased at 0.6. On the other hand, a hemoglobin threshold of $12 \mathrm{mg} / \mathrm{dl}$ allowed a distinction between two groups where the one with a pretreatment hemoglobin level of $\geq 12 \mathrm{mg} / \mathrm{dl}$ has a probability to respond to neoadjuvant chemotherapy of nearly seven times higher.
Fig. 1 shows the Kaplan-Meier actuarial survival curves by response to chemotherapy. Patients with a complete response to chemotherapy had a $100 \%$ survival rate compared to $93.1 \%$ for $\geq 50 \%$ responders and $53.8 \%$ for $<50 \%$ responders $(P=0.0001)$. Fig. 2 shows the KaplanMeier actuarial survival curves for hemoglobin threshold of $12 \mathrm{mg} / \mathrm{dl}$. Patients with a pretreatment hemoglobin level of $\geq 12 \mathrm{mg} / \mathrm{dl}$ showed a survival rate of $87 \%$ compared to $63 \%$ of patients with a lower hemoglobin level $(P=0.008)$.

\section{Discussion}

Neoadjuvant chemotherapy followed by radical surgery emerged as an alternative treatment to conventional radiotherapy (external beam therapy and brachytherapy) and more recently chemoradiotherapy for locally advanced cervical cancer. Awaiting results from ongoing trials, some efforts were made to predict in advance the response to chemotherapy of a subgroup of patients sensitive to the existing drugs to improve survival. There is increasing evidence that the response to chemotherapy is a good, or perhaps the most powerful, prognostic factor in locally advanced cervical cancer. In our report, patients who had a complete response to chemotherapy demonstrated a survival of $100 \%$ compared to $93.1 \%$ and $53.5 \%$ for reduction

Survival by hemoglobin level at diagnosis

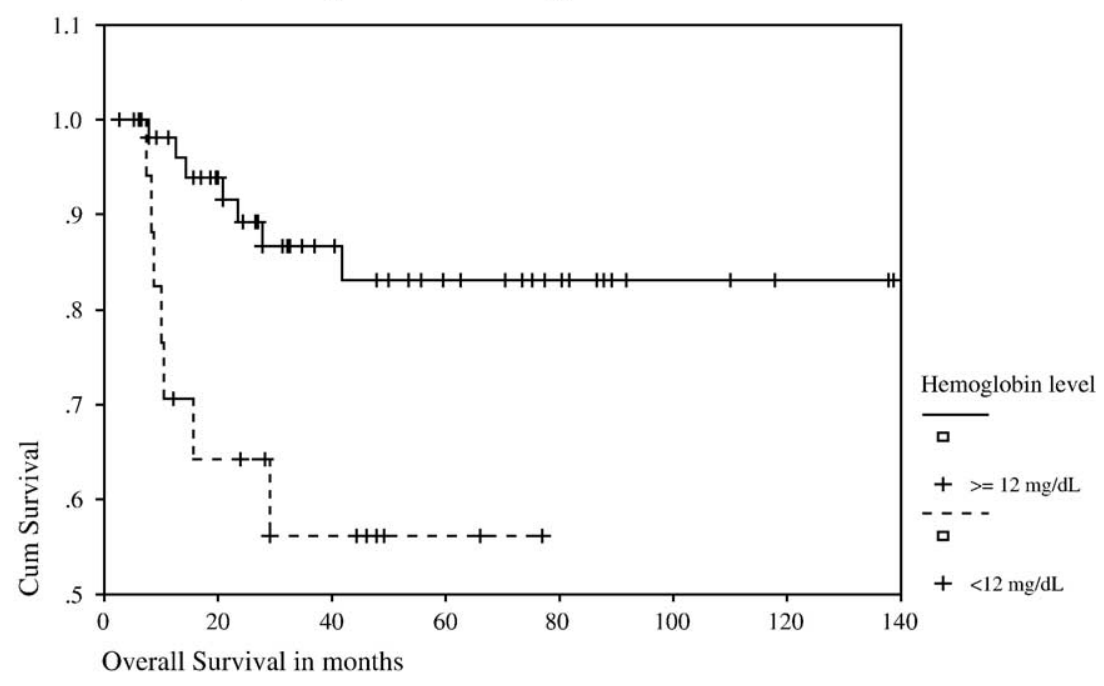

Survival Analysis for level of hemoglobin at diagnosis

\begin{tabular}{lrrcl}
\hline & $\begin{array}{r}\text { Total } \\
\text { HB }<12 \mathrm{mg} / \mathrm{dL}\end{array}$ & $\begin{array}{c}\text { Number } \\
\text { Events }\end{array}$ & $\begin{array}{l}\text { Number } \\
\text { Censored }\end{array}$ & $\begin{array}{l}\text { Percent } \\
\text { Censored }\end{array}$ \\
$\mathrm{HB} \geq 12 \mathrm{mg} / \mathrm{dL}$ & 54 & 7 & 47 & 87.04 \\
Overall & 73 & 14 & 59 & 80.82 \\
\hline
\end{tabular}

Log Rank : Statistic: $6.92 \quad \mathrm{p}=0.0085$

Fig. 2. Survival curves and analysis for this patient group stratified by hemoglobin level. 
of the tumor of $\geq 50 \%$ and $<50 \%$, respectively (log rank: $P$ value $=0.0001)$. Lacking reliable clinical predictive factors, some authors tested chemotherapy resistance by assessing biochemical factors such as serum levels of squamous cell carcinoma antigen [12], microvessel density $[6,7]$, oncogenes and tumor suppressor genes [13], and cyclooxygenase-2 [8]. Anemia is the most frequently observed hematological abnormality factor among cancer patients. Its impact on tumor biology is not well understood yet $[10,14]$. Suppression of erythroid progenitor cells by tumor cytokines (IL-6), changes in iron metabolism, alteration of erythropoietin response, or simply chronic hemorrhage are some of the mechanisms that have been associated with pretreatment tumor-associated anemia [15].

In the present study, we tested clinical pretreatment parameters and serum hemoglobin level to predict chemotherapy resistance. Neoadjuvant chemotherapy response was significantly more likely in patients with high pretreatment $\mathrm{Hb}$ values; the threshold of $12 \mathrm{mg} / \mathrm{dl}$ is shown to be a good cut-off between "optimal" response (complete and $\geq 50 \%$ response) and "non-optimal" response $(<50 \%$ reduction in tumor diameter). It has been reported repeatedly that anemia is associated with both decreased local control and overall survival in large numbers of patients affected by cervical cancer that are treated with radiotherapy [16-19]. One hypothesis is that hypoxic cell fraction of the tumor increases as a consequence of anemia and confers to these cellular clones a lowered degree of radiosensitivity [20]. Currently, there are few data available on the correlation between $\mathrm{Hb}$ pretreatment levels and response to neoadjuvant chemotherapy. In our report, we demonstrated a relationship between high levels of pretreatment serum hemoglobin and good response to neoadjuvant chemotherapy. Our preliminary data have to be confirmed by wider studies. Recombinant human erythropoietin (rhEPO) or blood transfusion can be used to increase blood $\mathrm{Hb}$ levels before chemotherapy and perhaps during the treatment with the aim of improving tumor oxygenation and convert cells to chemosensitivity. On the contrary, it may be supposed that hemoglobin levels may be useful to identify the more aggressive tumors which, because of chemoresistance, should not be treated with neoadjuvant chemotherapy followed by radical surgery.

\section{Conclusions}

Pretreatment serum hemoglobin level was found to be predictive of the response to chemotherapy, and a threshold of $12 \mathrm{mg} / \mathrm{dl}$ could be helpful to distinguish between "optimal" and poor response. If these results could be confirmed on a wider sample, clinical trials will need to be performed to determine whether to increase hemoglobin levels lead to improved local control rates and survival.

\section{References}

[1] Jemal A, Tiwari RC, Murray T, et al. Cancer statistics, 2004. CA Cancer J Clin 2004;54:8-29.

[2] Patterson F. Annual report on the results of treatment in gynecological cancer, vol. 20. Stockholm: International Federation of Gynecology and Obstetrics; 1991.

[3] Benedetti Panici P, Greggi S, Baiocchi G, et al. Neoadjuvant chemotherapy and radical surgery in locally advanced cervical cancer: prognostic factors for response and survival. Cancer 1991;67(2):372-9.

[4] Benedet J, Odicino F, Maisonneuve P, et al. Carcinoma of the cervix uteri: FIGO annual report on the results of treatment in gynecological cancer. J Epidemiol Biostat 1998;3:5-34.

[5] Benedetti Panici P, Greggi S, Colombo A, et al. Neoadjuvant chemotherapy and radical surgery versus exclusive radiotherapy in locally advanced squamous cell cervical cancer: results from the Italian multicenter randomized study. JCO 2002;20(1):179-88.

[6] Lyng H, Vorren AO, Sundfor K, et al. Intra- and intertumor heterogeneity in blood perfusion of human cervical cancer before treatment and after radiotherapy. Int J Cancer 2001 (Jun 20);96(3):182-90.

[7] Lyng H, Sundfor K, et al. Disease control of uterine cervical cancer: relationships to tumor oxygen tension, vascular density, cell density, and frequency of mitosis and apoptosis measured before treatment and during radiotherapy. Clin Cancer Res 2000 (Mar);6(3):1104-12.

[8] Ferrandina G, Lauriola L, Distefano MG, et al. Increased cyclooxygenase-2 expression is associated with chemotherapy resistance and poor survival in cervical cancer patients. JCO 2002;20(4):973-81.

[9] Obermair A, Cheuk R, Horwood K, et al. Anemia before and during concurrent chemoradiotherapy in patients with cervical carcinoma: effect on progression-free survival. Int J Gynecol Cancer 2003 (Sep-Oct);13(5):633-9.

[10] Van Belle SJ, Cocquyt V. Impact of haemoglobin levels on the outcome of cancers treated with chemotherapy. Crit Rev Oncol Hematol 2003 (Jul);47(1):1-11 [Review].

[11] Harrison L, Blackwell K. Hypoxia and anemia: factors in decreased sensitivity to radiation therapy and chemotherapy? Oncologist 2004;9(Suppl 5):31-40 [Review].

[12] Scambia G, Benedetti Panici P, Foti E, et al. Squamous cell carcinoma antigen: prognostic significance and role in the monitoring of neoadjuvant chemotherapy response in cervical cancer. J Clin Oncol 1994;12:2309-16.

[13] De Vita VT, Hellman S, Rosenberg SA. Cancer principles and practices of oncology, 5th ed. Philadelphia (PA): Lippincott-Raven; 1997.

[14] Mercadante S, Gebbia V, Marazzo A, Filosto S. Anaemia in cancer: pathophysiology and treatment. Cancer Treat Rev 2000;26:303-11.

[15] Spivak JL. Cancer-related anemia: its causes and characteristics. Semin Oncol 1994;21:3-8.

[16] Werner Wasik M, Schmid CH, Bornstein L, Ball HG, Smith DM, Madoc Jones H. Prognostic factors for local and distant recurrence in Stage I and II cervical carcinoma. Int J Radiat Oncol Biol Phys 1995;32:1309-17.

[17] Hong JH, Chen MS, Lin FJ, Tang SG. Prognostic assessment of tumor regression after external irradiation for cervical cancer. Int J Radiat Oncol Biol Phys 1992;22:913-7.

[18] Girinski T, Pejovic-Lenfant MH, Bourhis J, Campana F, Cosset JM, Petit C, et al. Prognostic value of hemoglobin concentrations and blood transfusions in advanced carcinoma of the cervix treated by radiation therapy: results of a retrospective study of 386 patients. Int $\mathrm{J}$ Radiat Oncol Biol Phys 1989;16(1):37-42.

[19] Grogan M, Thomas GM, Melamed I, Wong FLW, Pearcey RG, Joseph PK, et al. The importance of hemoglobin levels during radiotherapy for carcinoma of the cervix. Cancer 1999;86:1528-36.

[20] Henke M, Bechtold C, Momm F, Dörr W, Guttenberger R. Blood hemoglobin level may affect radiosensitivity-Preliminary results on acutely reacting normal tissues. Int J Radiat Oncol Biol Phys 2000; 48(2):339-45. 